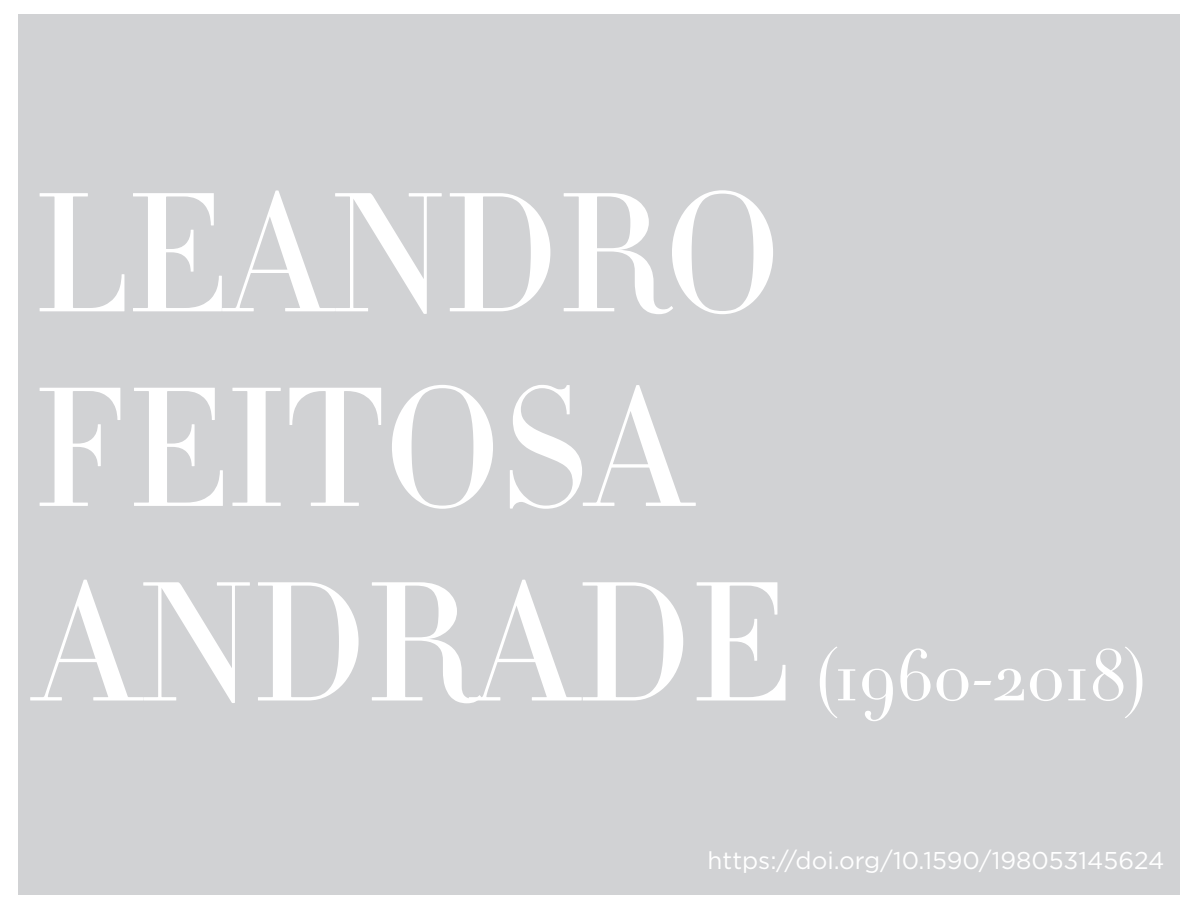

\title{
A TRADUÇÃO DA SENSIBILIDADE PROFISSIONAL NA LUTA PELA IGUALDADE DE GÊNERO
}

\section{SANDRA UNBEHAUM'}

Nunca se conhece totalmente uma pessoa em toda a sua plenitude, mesmo que a conheçamos há décadas. Esse pensamento ocorreu-me quando fui levada a rememorar minha relação de amizade e coleguismo profissional com Leandro Feitosa, em busca de inspiração para escrever uma justa homenagem a ele, em razão de sua precoce morte, em maio de 2018. Leandro trabalhou na Fundação Carlos Chagas (FCC) desde 2003 até 2012, particularmente no Programa Internacional de Bolsas de Pós-Graduação da Fundação Ford (International Fellowships Program - IFP), coordenado por Fúlvia Rosemberg. Eu conheci Leandro muito antes disso, em 1996 ou 97, no Grupo de Estudos sobre Sexualidade Masculina e Paternidade (Gesmap), criado pela Ecos - Comunicação em Sexualidade, em 1995, com apoio da Fundação Ford e da Fundação MacArthur. O Gesmap, como era conhecido, fora um dos primeiros grupos no Brasil a dedicar-se a aprofundar conhecimentos sobre meninos e jovens rapazes, numa perspectiva relacional da teoria de gênero. Com o objetivo de refletir coletivamente sobre a construção social das masculinidades, 
o grupo reunia 13 pesquisadoras/res, profissionais de diversas áreas que atuavam em projetos de pesquisa e intervenção, em particular no campo da saúde e da prevenção. Leandro era um deles. Nosso grupo reunia-se mensalmente para atividades de estudos, de debates com acadêmicos nacionais e internacionais. Em pouco tempo, o Gesmap viu a necessidade de ampliar o diálogo e a disseminação de nossas reflexões, o que nos levou a ter como meta a escrita de uma coletânea que reunisse e sistematizasse as discussões do grupo, apresentando as metodologias abraçadas em nossas pesquisas e intervenções, mas também trouxesse relatos de experiências pessoais e profissionais no trabalho com masculinidades. É nesse eixo que se enquadra a rica e incomum contribuição de Leandro. Incomum porque o artigo relata a experiência vivida por ele na intervenção com mulheres na prostituição em atividades de prevenção de doenças sexualmente transmissíveis (DSTs/Aids), saúde e direitos. Naquela época, ter homens (heterossexuais) trabalhando numa perspectiva de direitos humanos das mulheres e com a proposta de ressignificar as representações masculinas, sobretudo aquelas relacionadas à prostituição, não era usual e, por vezes, criticado, inclusive pelo movimento feminista. É nesse relato de experiência que encontro a sensibilidade profissional, numa perspectiva masculina, e minha melhor lembrança de Leandro, que corresponde à sua lealdade e marca profissional:

O impacto inicial atordoa como flashes. Vacila-se em enfrentar o
olhar objetivo dessas mulheres. Seus olhares são como lâminas afia-
das que cortam qualquer barreira ideológica e intelectual. Despem-
nos e tocam nos nossos instintos mais básicos de satisfação.
Após esse estonteante impacto, mais ou menos realinhado, pro-
curo ampliar o meu olhar. Na conversa entre elas, na relação com
os filhos, num momento de descanso, na hora das refeições,
com alguém de estima. Conhecê-las não no papel de mulheres na
prostituição. Como olham ao pedir a um padre benção, a um filho,
atenção, à mãe, opinião, ao balconista, comida, ao médico, saúde,
ao companheiro, amor? Quem sabe assim poderei desconstruir a
dura visão do impacto inicial. Desvio meu olhar do desconcertante
olhar da prostituta e procuro observar o olhar da mãe, da filha,
da companheira, da amiga, da cliente. Procuro o olhar cansado, o
olhar alegre, descomprometido, criança, preocupado. Na procu-
ra de ver outros olhares, reajusto o meu foco para outros papéis.
(ANDRADE, 1998, p. 275-276)

O tema da prostituição o levou a pesquisar na pós-graduação, no campo da Psicologia Social, a exploração sexual de crianças e adolescentes na mídia. Orientado por Fúlvia Rosemberg, Leandro analisou vasto material jornalístico atento ao tratamento dado ao tema, cujo resultado 
é o estigma de crianças e adolescentes pobres, sem o devido questionamento das determinações sociais, éticas e psicológicas que levam adultos a elegerem parceiros sexuais não adultos. A pesquisa levou-o diretamente ao doutorado e à premiação como melhor tese, resultando na publicação de um livro, com o apoio da Fapesp (ANDRADE, 2004).

Logo após o doutorado, Leandro atuaria na FCC, cuidando de toda a organização e sistematização de uma base de dados do Programa Bolsa, além de gerenciar o processo de difusão, seleção e atendimento às candidaturas. Várias eram as responsabilidades assumidas, inclusive a produção, em coautoria com Fúlvia Rosemberg, de artigos acadêmicos (ROSEMBERG; ANDRADE, 2013, 2008). Num deles, publicado em Cadernos Pagu (2008), a partir do perfil de candidatos ao Programa Bolsa, escreveram um ensaio no qual discutem a sub-representação das mulheres no ensino superior e na pós-graduação, contraditório ao melhor desempenho educacional delas. Nesse artigo, Leandro desenvolve junto com sua mentora importante discussão sobre a não sincronia das desigualdades sociais, chamando nossa atenção para o efeito não cumulativo das desigualdades de gênero, raça, idade e classe e o risco de simplificar as incoerências existentes nas instituições educacionais.

A escuta e o olhar acurados e críticos do cotidiano no Programa Bolsa se fez presente em sua análise da experiência vivida em uma década, num relato fiel ao que representou o desenvolvimento de uma metodologia inovadora de ação afirmativa para a pós-graduação e para a qual Leandro muito contribuiu:

No cotidiano do Programa todos e tudo foram alvos de altas expectativas e exigências, mesmo assim, nem sempre agradamos e nem sempre estávamos satisfeitos, muitas vezes, com nós mesmos - a insatisfação produtiva foi, e ainda é, a tônica na gestão Insatisfação que levou a uma busca, muitas vezes, obsessiva de integrar parâmetros éticos, teóricos, técnicos, profissionais e humanos. E por falar em humano, todos foram por demais humanos: pacientes, metódicos, tolerantes, eufóricos, apressados, estressados, preocupados, desesperados. Erramos, por várias vezes, erramos, mas nunca o erro foi tão bem vindo, visto, revisto, avaliado, destrinchado e, na maioria das vezes, superado. O Programa deixa tatuado em todos, que por aqui passaram, lições de empenho, dedicação, compromisso, trabalho, respeito e ética. Uma etapa da vida, muito bem vivida. (Relatório Final do Programa Internacional de Bolsas de Pós-Graduação da Fundação Ford, 2012, p. 161)

Em paralelo à sua atuação no Programa Bolsa, Leandro coordenou grupos de homens autores de violência contra mulheres em uma organização feminista, no Coletivo Feminista Sexualidade e Saúde (desde 
2009), ao lado do filósofo e amigo Sérgio Barbosa, também integrante do Gesmap. O tema da violência se fez presente na trajetória profissional desde a conclusão da graduação em Psicologia na PUC-SP. Ao lado de Heleieth Saffioti, então professora do Programa de Ciências Sociais naquela universidade, colaborou nas pesquisas "A violação do tabu do incesto" e "Violência doméstica: uma questão de polícia ou da sociedade". Mas foi a violência vivida ou praticada por homens que tornaria Leandro uma referência nos estudos e intervenção com foco nas masculinidades (ANDRADE, 2014; OLIVEIRA et al., 2015). Com a aprovação, em 2006, da Lei n. 11.340/06, conhecida como lei Maria da Penha (BRASIL, 2006), a experiência de Leandro na intervenção nas áreas de saúde e prevenção, bem como sua inserção no debate crítico de gênero sob a perspectiva masculina, como uma referência para pensar as relações sociais e sexuais, levou-o a coordenar grupos reflexivos com homens, colaborando na construção de uma metodologia de enfrentamento da violência contra as mulheres. Nessa perspectiva, os homens são levados a assumir sua responsabilidade pelo ato violento, contrapondo-se à patologização ou naturalização da violência como comportamento masculino; ao contrário, intenta-se a ressignificação do comportamento e compreensão dos processos de constituição da violência.

Essa breve memória não traduz a integra da pessoa, do psicólogo, do colega, do homem dedicado a mostrar para outros homens, como ele, a existência de diversas possibilidades de ser, de existir e de conviver, não sendo a violência contra as mulheres e contra outros homens, e, em consequência, contra si mesmos a única narrativa de comunicação possível. Apazigua imaginar que a sensibilidade do Leandro possa ter tocado a outros tantos homens.

\section{REFERÊNCIAS}

ANDRADE, Leandro Feitosa. Grupos de homens e homens em grupos: novas dimensões e condições para as masculinidades. In: BLAY, Eva Alterman (Org.). Feminismos e masculinidades. 1. ed. São Paulo: Cultura Acadêmica, 2014. p. 173-210.

ANDRADE, Leandro Feitosa. Prostituição infanto-juvenil na mídia: estigmatização e ideologia. 1. ed. São Paulo: Educ, 2004. v. 1. 252 p.

ANDRADE, Leandro Feitosa. Uma relação diferente entre homens e mulheres na prostituição feminina. In: ARILHA, Margareth; UNBEHAUM, Sandra; MEDRADO, B. (Org.). Homens e masculinidades: outras palavras. São Paulo: 34, 1998. p. 271-284.

BRASIL. Presidência da República. Casa Civil. Lei n. 11.340, de 7 de agosto de 2006. Disponível em: <http://www.planalto.gov.br/ccivil_03/_ato2004-2006/2006/lei/111340.htm>. Acesso em: 13 jun. 2018.

FUNDAÇÃO CARLOS CHAGAS. Relatório Final do Programa Internacional de Bolsas de Pós-Graduação da Fundação Ford: Brasil. São Paulo, 2012.

OLIVEIRA, Isabela V. de; ANDRADE, Leandro F.; PRATES, Paula L.; FURTADO, Tales M. Tensões e desafios na intervenção com homens autuados pela Lei Maria da Penha: o caso dos grupos reflexivos no coletivo feminista sexualidade e saúde. Revista do Gênero \& Direito, v. 1, p. 219-240, 2015. 
ROSEMBERG, Fúlvia M. de B. M.; ANDRADE, Leandro F. Indígenas no Programa Internacional de Bolsas de Pós-Graduação da Fundação Ford e os aportes do Trilhas de Conhecimento. In: LIMA, Antonio Carlos de Souza; BARROS, Maria Macedo (Org.). Povos indígenas e universidade no Brasil. 1. ed. Rio de Janeiro: E-papers, 2013. p. 133-162.

ROSEMBERG, Fúlvia M. de B. M.; ANDRADE, Leandro F. Ação afirmativa no ensino superior brasileiro: a tensão entre raça/etnia e gênero. Cadernos Pagu, Campinas, n. 31, p. 419-438, 2008. 